of the latter to the administration of experimental drugs designed to lower pulmonary vascular resistance. There may also be a temptation to increase the peak inspiratory pressures in such a situation. In the case described, any of the above measures might have had dire consequences.

We have seen hypoxia relieved by stopping IPPV on previous occasions, but have been unable to document the event. We have also seen patients with bronchopulmonary dysplasia whose early neonatal course was similar to that described above.

The indications for IPPV were obscure and this case serves as a reminder that IPPV should not be undertaken without good reason. It also emphasises the importance of proper assessment of a patient after transfer from another hospital.

\section{References}

1 Andersen M N, Kuchiba K. Depression of cardiac output with mechanical ventilation. $J$ Thorac Cardiovasc Surg 1967; 54: 182-90.

2 Beddis I R, Collins P, Levy N M, Godfrey S, Silverman M.
A new technique for the servo-control of arterial oxygen tension in preterm infants. Arch Dis Child 1979; 54: 278-80.

3 Morgan B C, Martin W E, Hornbein T F, Crawford E W, Guntheroth W G. Hemodynamic effects of intermittent positive pressure respiration. Anesthesiology 1966; 27: 585-90.

4 West J B. Ventilation/blood flow and gas exchange. 3rd ed. Oxford: Blackwell Scientific, 1977: 15-32.

5 Lamy M L, Fallat R J, Eberhart R C, et al. Decreased left ventricular output with PEEP in normal men and dogs in closed and open chest conditions (abstract). Am Rev Respir Dis 1979; 119: No. 4, part 2, 377.

- Wise $\mathbf{R}$ A, Robotham J L, Bromberger-Barnea B, Permutt S. Mechanism of elevation of left atrial pressure due to PEEP (abstract). Am Rev Respir Dis 1979; 119: No. 4, part 2, 392.

7 Milner A D, Saunders R A, Hopkin I E. Effect of continuous distending pressure on lung volume and lung mechanics in the immediate neonatal period. Biol Neonate 1977; 31 : 111-5.

8 Nelson R M, Egan E A, Eitzman D V. Increased hypoxemia in neonates secondary to the use of continuous positive airway pressure. J Pediatr 1977; 91 : 87-91.

Correspondence to $\mathrm{Dr} M$ Silverman, Department of Paediatrics and Neonatal Medicine, Hammersmith Hospital, Du Cane Road, London W12 OHS.

\title{
Eucalyptus oil poisoning
}

\author{
S PATEL AND J WIGGINS
}

Department of Paediatrics, East Birmingham Hospital, Birmingham

SUMMARY Accidental ingestion of eucalyptus oil by a 3-year-old boy caused profound central nervous system depression within $\mathbf{3 0}$ minutes, but he recovered rapidly after gastric lavage. The extreme toxicity of eucalyptus oil is emphasised.

Eucalyptus oil is a traditional remedy for a variety of common ailments, particularly of the respiratory tract. It is cheap, freely available, and found in many households. However, its extreme toxicity is not generally appreciated and reports of poisonings are rare. With this in mind we report a recent ingestion of eucalyptus oil that was nearly fatal.

\section{Case report}

A 3-year-old Muslim boy was seen within 30 minutes of ingesting about $10 \mathrm{ml}$ eucalyptus oil. On examination he was deeply comatose and his breath smelt strongly of eucalyptus. The pupils were constricted, muscle tone was markedly reduced, and his tendon reflexes could not be elicited. His respirations were shallow and irregular at a rate of $10 / \mathrm{min}$. The pulse rate was 70 beats $/ \mathrm{min}$ and the blood pressure $75 / 40 \mathrm{mmHg}$. Biochemical investigations on admission included a serum urea of $6.3 \mathrm{mmol} / 1$ $(38 \mathrm{mg} / 100 \mathrm{ml})$, with normal electrolytes. Initial treatment included the insertion of a cuffed endotracheal tube (which produced no gag reflex), and gastric lavage with sodium bicarbonate solution. Sodium sulphate $100 \mathrm{ml}$ was left in the stomach as a cathartic.

By 2 hours after admission his pulse, blood pressure, and respiration rate had gradually returned to normal. After 5 hours consciousness had gradually been regained, and by 24 hours physical examination was normal apart from a faint smell of eucalyptus on the breath. Urinary output remained satisfactory throughout. He was discharged home 48 hours after admission. 


\section{Discussion}

The safe adult dosage of eucalyptus oil as an internal medicine is quoted as 0.06 to $0.2 \mathrm{ml} .{ }^{1}$ Death in adults has occurred after 4 or $5 \mathrm{ml}$, and is usual after $30 \mathrm{ml}^{2}$ Recovery however, has been reported after the ingestion of 120 to $220 \mathrm{ml} .^{3}$ The toxic effects of ingestion of this toxic, volatile hydrocarbon are rapid in onset and extensive. They include a burning sensation in the mouth and throat, abdominal pain, and spontaneous vomiting which may be delayed up to 4 hours after ingestion. ${ }^{4}$ Respiratory problems include bronchospasmand tachypnoea, with dangerous respiratory depression following severe intoxication. Central nervous system involvement includes diminution or loss of reflexes, and depression of consciousness which may progress to coma. Convulsions are rare in the adult but may be prominent in the child. ${ }^{5}$ Direct nephrotoxicity may follow the ingestion of large volumes and cutaneous manifestations have been described. ${ }^{6}$

The management of eucalyptus oil poisoning ${ }^{3}$ is mainly supportive. Attempts to induce vomiting in the child should be avoided and the possibility of vomiting and aspiration of oil implies that gastric lavage should be performed with great care, a cuffed endotracheal tube being inserted in the presence of central nervous system depression. Urinary output should be carefully monitored, particularly when hypotension is present or if large volumes of oil have been ingested. In severe poisoning, peritoneal or haemodialysis is of value. ${ }^{3}$ The role of catharsis has not been adequately assessed.

Although the use of eucalyptus oil is becoming less fashionable, the hazards of its ingestion remain, particularly in the child. Our case serves as a reminder of the severe toxicity of this substance, illustrating the rapid onset of its severe respiratory and central nervous system effects.

We thank Dr M H Winterborn for permission to report this patient.

\section{References}

1 Martindale W. The extra pharmacopoeia. 27th ed. London: Pharmaceutical Press, 1977.

2 MacPherson J. The toxicology of eucalyptus oil. Med J Aust 1925; ii: 108-10.

${ }^{3}$ Gurr F W, Scroggie J G. Eucalyptus oil poisoning treated by dialysis and mannitol infusion with an appendix on the analysis of biological fluids for alcohol and eucalyptol. Australas Ann Med 1965; 14: 238-49.

4 Foggies W. Eucalyptus oil poisoning. Br Med J 1911; i: $359-60$.

5 Chun L T. Accidental poisoning in children, with special reference to kerosene poisoning. Hawaii Med J 1951; 11: 83-7.

${ }^{6}$ Kirkness W R. Poisoning by oil of eucalyptus. $\mathrm{Br} \mathrm{Med} \mathrm{J}$ 1910; i: 261.

Correspondence to $\mathrm{Dr} \mathbf{M} \mathbf{H}$ Winterborn, Department of Paediatrics, East Birmingham Hospital, Bordesley Green East, Birmingham B9 5ST.

\section{Factor $\mathrm{X}$ deficiency in the neonatal period}

\section{S J MACHIN, M R WINTER, S C DAVIES, AND I J MACKIE}

Department of Haematology, Middlesex Hospital, and Department of Haematology, Central Middlesex Hospital, London

SUMMARY An infant with a severe deficiency of factor $X$ presented in the neonatal period with uncontrollable bleeding from heel prick sites, spontaneous bruising, and haematoma. The deficiency was controlled by infusions of dried human factors II, IX, and $X$ concentrate; the half-life of the infused factor $\mathrm{X}$ material is only 18 hours. Despite prophylactic weekly infusions of factor $X$ concentrate, the child developed a fatal intracerebral haemorrhage when only 4 months old. Coagulation studies on both parents and the elder sister showed no obvious coagulation abnormality.
Factor $\mathrm{X}$ deficiency is a rare bleeding disorder inherited as an autosomal incompletely recessive trait. Usually the deficient state is clinically relatively slight, and for effective haemostasis a factor $\mathrm{X}$ level $>10 \%$ is thought to be adequate. ${ }^{1}$

\section{Case report}

An Indian girl was born after an uneventful pregnancy which had progressed to term. She was clinically well and delivery had been normal. A prophylactic intramuscular injection of $1 \mathrm{mg}$ vitamin $K_{1}$ was given one hour after birth into the 